\title{
Auf voller Höhe seines Könnens arbeiten*
}

\section{Richard O. Binswanger}

Der Autor arbeitet als Konsiliararzt für Radiologie an den Kantonsspitälern Münsterlingen und Baden.

\section{* Auch ein Beitrag zur Verminderung des Ärzte- mangels}

Korrespondenz:

Dr. med. Richard O. Binswanger Führungsschule Bodensee Münsterlingen

Oberer Seeweg 9

CH-8597 Landschlacht

r.binswanger[at]bluewin.ch

www.fsb-spital.ch
Die Gesundheitsindustrie ist nach wie vor eine Wachstumsbranche. Ein Ende ist nicht abzusehen. Die Zahl der mit kranken Menschen arbeitenden Personen nimmt ständig zu. Für Gesundheitsunternehmen und die Beschäftigten wird dies aus wirtschaftlichen Gründen positiv bewertet. Warum aber will sich keine Zufriedenheit einstellen? Wir bilden viel zu wenig Gesundheitspersonal aus, namentlich Ärzte. Die Lücken werden durch Zuwanderung gefüllt, ein beschämender Zustand. Neben grosser Sinnerfüllung gibt es auch im Gesundheitswesen viel Frustration und Unzufriedenheit. Diese nähren sich zum Teil aus der Tatsache, dass den Mitgliedern der mittleren und unteren Chargen der Zugang zu (delegierter) ärztlicher Tätigkeit verwehrt bleibt.

\section{Delegierte ärztliche Tätigkeit - Potential nicht ausgeschöpft}

Es gibt sie schon lange: Cytologietechniker befunden Ausstriche vom Gebärmutterhals. Und zwar abschliessend bei Normalbefunden. Sie werden dabei unterstützt und stichprobenweise kontrolliert von Fachärzten. Pflegende spritzen, zum Teil auch gefährliche Medikamente. Anästhesiepfleger überwachen Patienten, wenn der Anästhesist im benachbarten Operationssaal intubiert. Es wären aber noch viel mehr delegierte Tätigkeiten möglich. Speziell ausgebildete und geprüfte Mitarbeiter aus Pflege und anderen Gesundheitsberufen könnten eingesetzt werden als Screenings-Koloskopeure, Erstleser von Screeningmammographien, Nurse Practitioners (die es zum Beispiel in Kanada und Australien schon lange gibt). Ein Fachmann für Operationstechnik kann lernen, einen Bauch zu öffnen und wieder zu verschliessen. Die Liste lässt sich beliebig fortsetzen. Es ist auch wenig sinnvoll, dass Apothekerhelferinnen nur wegen der Apothekerpauschale jedes verkaufte Medikament ihrem Chef zeigen müssen.

\section{Ärzte in der Defensive}

Wegen starrer Ausbildungsgrenzen. Wegen des Geldes (Nurse Practitioners sind kostengünstiger). Aus Tradition. Aus Bequemlichkeit. Die Ärzte stehen neuen Lösungen im Weg. Behindern den Fortschritt.

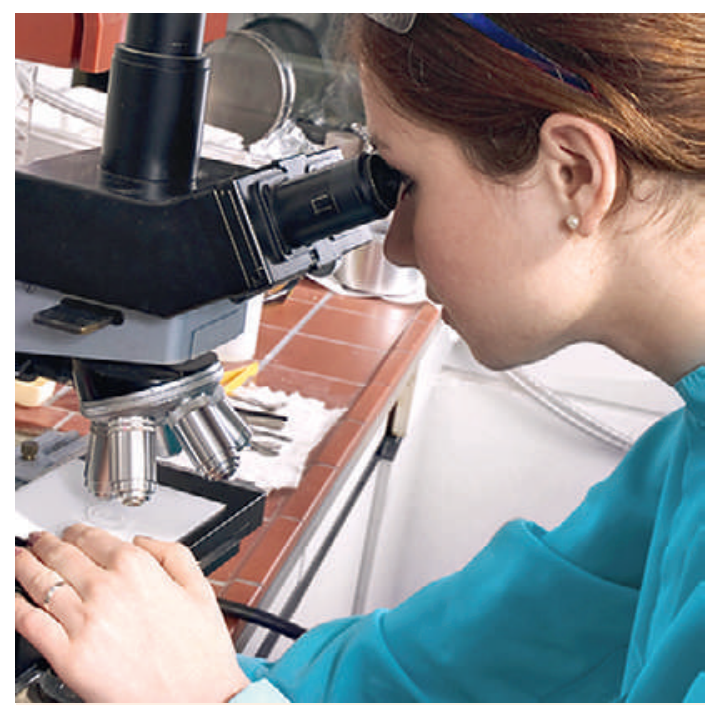

Unausgeschöpftes Potential: Diverse ärztliche Tätigkeiten könnten delegiert werden - zum Wohl der Patienten und des Gesundheitswesens.

\section{Was gewinnen wir?}

Viel und Wichtiges. Die Ärzte könnten sich auf Tätigkeiten konzentrieren, die zwingend nur von ihnen ausgeübt werden müssen. Es gäbe weniger Routine. Der Arztberuf würde interessanter, vielleicht auch vielfältiger. Für die anderen Gesundheitsberufe wären die neuen Möglichkeiten attraktiv. Sie erweitern deren Tätigkeitsgebiet. Sie führen zu beruflichem und persönlichem Wachstum. Und zu mehr Freude und Befriedigung. Der Ärztemangel würde gemildert. Die Raubzüge nach gutausgebildeten Ärzten im Ausland nähmen ab. Die Krankenkassenprämien würden etwas langsamer steigen. Krankenkassen und Politiker würden die Initiative der Ärzte begrüssen. Letzere würden sich als konstruktive Kraft manifestieren.

\section{Fazit}

Bei der Ausweitung delegierter ärztlicher Tätikeit gibt es nur Gewinner. Jeder im Gesundheitswesen «works at the full hight of his capacity». Es lohnt sich für alle, wenn die Ärzteschaft diesen Gedanken aufgreift und umsetzt. 